\title{
CARACTERIZAÇÃO DE AÇO ZINCADO PRÉ-FOSFATIZADO CSN PARA APLICAÇÃO EM ESTAMPAGEM DE PEÇAS CRÍTICAS NO SEGMENTO AUTOMOTIVO*
}

\author{
Alberto Nei Carvalho Costa ${ }^{1}$ \\ José Eduardo Ribeiro de Carvalho \\ Fabiano Augusto Vallim Fonseca ${ }^{3}$ \\ Marcelo Pereira de Oliveira ${ }^{4}$ \\ Neilor da Silva Oliveira ${ }^{5}$
}

\section{Resumo}

Devido às novas tendências de design de carrocerias de automóveis, as peças pertencentes a estas carrocerias apresentam características de fabricações cada vez mais críticas, principalmente relacionadas ao processo de estampagem. Uma forma de atuar neste processo para evitar perdas de produtividade, principalmente com o rompimento do material, é atuar na lubricidade entre o material e o ferramental do equipamento. A aplicação do óleo lubrificante na bobina de aço é uma forma de atuar na lubricidade, mas devido à criticidade de estampagem que determinadas peças apresentam, somente o óleo lubrificante não é suficiente para este fim. Visando atender essa necessidade, a CSN e seus fornecedores desenvolveram um sistema de lubrificante para seus aços, conhecida como tecnologia de pré-fosfato. Este trabalho tem como objetivo apresentar as vantagens fornecidas pelo aço pré-fosfatizado no que se refere a estampagem crítica de peças automotivas, bem como avaliar o seu impacto no processo de pintura automotiva. Como resultado verificou-se que a camada de pré-fosfato impactou na redução do coeficiente de atrito do aço zincado de forma suficiente para confecção de peças críticas de carrocerias de automóveis. Verificou-se também que o filme de pré-fosfato é totalmente removido na etapa de desengraxe do processo pintura automotivo, não prejudicando as etapas subseqüentes do processo: fosfatização e pintura.

Palavras-chave: Estampagem; Aço zincado; Coeficiente de atrito.

\section{CHARACTERIZATION OF GALVANIZED STEEL CSN PRE-PHOSPHATE FOR APPLICATION ON STAMPING CRITICAL PARTS IN THE AUTOMOTIVE SEGMENT Abstract}

Due to new design trends of car bodies, parts belonging to these bodies exhibit characteristics of fabrications increasingly critical, especially related to the stamping process. One way to perform this process to avoid productivity losses, especially in relation to the rupture of the material, is to work in lubricity between the material and the tooling equipment. The application of lubricant oil on the steel coil is a way to act in the lubricity, but due to the criticalness of stamping certain parts show, just the lubricating oil is not sufficient for this purpose. Aiming at responding this need, CSN and its suppliers have developed a system lubricant for your products, known as pre-phosphate technology. This study aims to show the advantages provided by the pre-phosphatized steel as regards the critical stamping automotive parts, as well as evaluating their impact on the automotive painting process. As the result it was found that the film of prephosphate has impacted in a decrease in the coefficient of friction of galvanized steel sufficiently for making critical parts of car bodies. It was also observed that the prephosphate film is completely removed in the degreasing step of painting automotive process, not harming the subsequent steps: phosphating and painting.

Keywords: Stamping, Galvanized Steel, Coefficient of Friction

Eng ${ }^{\circ}$ Químico, M.Sc., Especialista de Desenvolvimento de Produtos, CSN, Volta Redonda, RJ, Brasil. Eng ${ }^{\circ}$ Metalúrgico, M.Sc., Gerente de Desenvolvimento de produtos, CSN, Volta Redonda, RJ, Brasil. Eng ${ }^{\circ}$ Metalúrgico, Gerente de Desenvolvimento Programação e Qualidade, Volta Redonda, RJ, Brasil. Eng ${ }^{\circ}$ Metalúrgico, Engenheiro de Desenvolvimento Senior, CSN, Volta Redonda, RJ, Brasil.

Técnico Químico, Técnico de Laboratório, CSN, CSN, Volta Redonda, RJ, Brasil.

\footnotetext{
* Contribuição técnica ao $51^{\circ}$ Seminário de Laminação - Processos e Produtos Laminados e Revestidos, 28 a 31 de outubro de 2014, Foz do Iguaçu, PR, Brasil.
} 


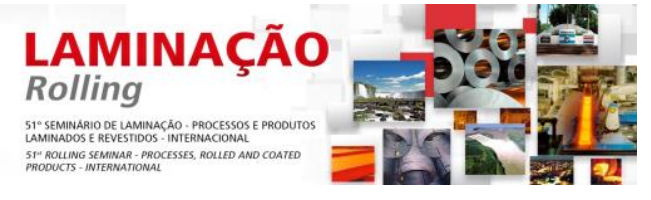

\section{INTRODUÇÃO}

A fosfatização é um dos métodos mais importantes do setor de tratamento de superfície sendo largamente aplicada para as seguintes finalidades:

- Como base para pintura;

- Para resistência à corrosão, após aplicação de óleos, graxas ou ceras;

- Para resistência ao desgaste;

- Para facilitar as operações de conformação mecânica;

- Para resistência à corrosão sem proteção suplementar.

O uso de camadas fosfatizadas nas operações de conformação é conhecido desde 1934. Durante a Segunda Guerra Mundial, a fosfatização foi muito utilizada na Alemanha nas operações de conformação de metais ferrosos, particularmente para produção de munições. De 1944 até 1960, a importância do uso de camadas fosfatizadas para conformação foi aumentando. Em 1960, a importância da fosfatização para conformação foi comparável a da resistência à corrosão. No entanto, a partir de 1960, a aplicação das camadas fosfatizadas como base de pintura foi superando à da conformação devido ao crescente aumento da indústria automobilística, que utiliza camadas fosfatizadas para melhorar o desempenho de tinta.

A conformação mecânica engloba muitos processos, dentre os quais se pode citar: trefilação de fios, extrusão de tubos, conformação a frio, estampagem, etc.... Todas estas operações envolvem deformação sem um pré-aquecimento do metal e numa condição em que a temperatura durante a deformação não ultrapassa a temperatura de $500^{\circ} \mathrm{C}$. Assim, todas estas operações requerem uma boa lubrificação da superfície a ser deformada, o que só se consegue através da aplicação de um tratamento de conversão, visto que estas camadas aumentam a capacidade de retenção dos lubrificantes. Entre os tratamentos de conversão, a fosfatização é uma das mais eficientes. Abaixo, seguem algumas vantagens [1,2] do uso de camadas fosfatizadas no processo de conformação de metais:

- Camadas fosfatizadas favorecem a retenção de lubrificantes: Superfícies fosfatizadas apresentam uma capacidade de retenção de óleo muito maior do que superfície não-fosfatizadas. Utilizando o mesmo tipo de óleo, foi verificado [2] que uma superfície de aço que é capaz de reter $1 \mathrm{~g} / \mathrm{m}^{2}$ de óleo passa a reter 2,3 $\mathrm{g} / \mathrm{m}^{2}$ após fosfatização. Dependendo de tipo de óleo utilizado e da rugosidade superficial inicial do substrato, a capacidade de retenção pode ser ainda maior;

- Camadas fosfatizadas reduzem de maneira significada o coeficiente de fricção: A grosso modo $50 \%$ da energia necessária, para uma determinada operação de conformação, é gasta na friç̧ão. A fosfatização, mais a lubrificação reduzem muito o coeficiente de friç̧ão e portanto este gasto de energia. Por exemplo, com um lubrificante emulsionável e sob pressão de $1440 \mathrm{~N} / \mathrm{m}^{2}$, o fosfato de zinco determina uma redução do coeficiente de fricção de 0,70 para 0,043 [2];

- Camadas fosfatizadas não sofrem destacamento mesmo sob deformação severa e não são desgastadas: Camadas fosfatizadas são altamente aderentes e esta aderência continua durante todo o processo de deformação. Os cristais de fosfato de zinco apresentam uma micro-dureza comparável ao do substrato de aço $\left(1300 \mathrm{~N} / \mathrm{mm}^{2}\right)$ e praticamente não são desgastadas durante a deformação. Acreditase que o início das operações de deformação, parte dos cristais de fosfatos são transformados em um pó finamente dividido. Este pó fino, juntamente com o lubrificante, forma uma pasta que adere sobre a camada remanescente de fosfato formando uma superfície vítrea. Após uma deformação de 15\%, não se detecta mais

\footnotetext{
* Contribuição técnica ao $51^{\circ}$ Seminário de Laminação - Processos e Produtos Laminados e Revestidos, 28 a 31 de outubro de 2014, Foz do Iguaçu, PR, Brasil.
} 


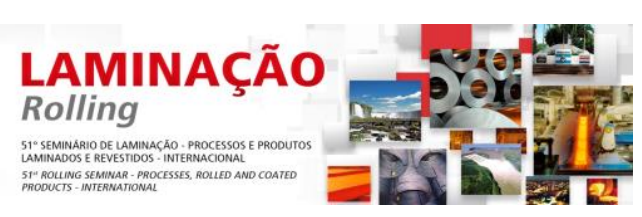

Velocidade de ebutimento: $5 \mathrm{~mm} / \mathrm{min}$

\subsection{Determinação do Coeficiente de Atrito}

O coeficiente de atrito foi avaliado com a utilização do equipamento (Altek - modelo 9505A1), conforme o procedimento utilizado em empresa do setor siderúrgico. Tal procedimento consiste basicamente em arrastar horizontalmente um bloco padrão de $2 \mathrm{~kg}$ com contato esférico, a uma velocidade constante, conforme o manual de operação do equipamento. A força necessária para deslocar o bloco é mensurada por uma célula de carga. A figura 2 apresenta a imagem do equipamento utilizado para a realização da medida do coeficiente de atrito.

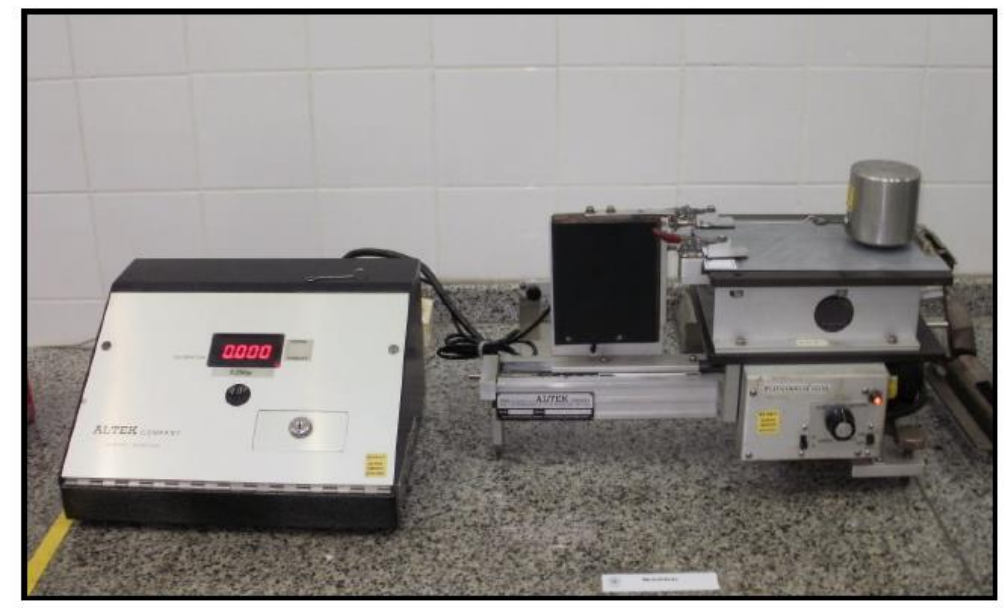

Figura 2: Imagem do equipamento utilizado para a medição do coeficiente de atrito

\subsection{Ensaio de Desengraxe: Simulação do Processo de Desengraxe da Linha de Pintura Automotiva}

Para avaliação do potencial de remoção do filme de pré-fosfato, foi realizada uma simulação em escala laboratorial do processo industrial de desengraxe automotivo. O processo de desengraxe é realizado em 2 estágios. A Tabela 1 apresenta os parâmetros de cada estágio adotado para a simulação em laboratório.

Tabela 1. Parâmetros empregados nos ensaios laboratoriais para cada estágio do processo industrial de desengraxe.

\begin{tabular}{|c|c|c|c|c|c|}
\hline Estágio & $\begin{array}{c}\text { Volume } \\
\text { da solução } \\
(\mathrm{l})\end{array}$ & $\begin{array}{c}\text { Massa de } \\
\text { Desengraxante } \\
(\mathrm{g})\end{array}$ & $\begin{array}{c}\text { Volume de } \\
\text { Tensoativo } \\
(\mathrm{ml})\end{array}$ & $\begin{array}{c}\text { Temperatura( }{ }^{\circ} \\
\mathrm{C})\end{array}$ & $\begin{array}{c}\text { Tempo } \\
\text { Imersão } \\
(\mathrm{min})\end{array}$ \\
\hline 1 & 4,0 & 51,2 & 5,12 & $50 \pm 5$ & 3 min $50 \mathrm{~s}$ \\
\hline 2 & 4,0 & 40,0 & 4,00 & $50 \pm 5$ & 3 min $50 \mathrm{~s}$ \\
\hline
\end{tabular}

\subsection{Determinação do Teor de Fósforo do Filme de Pré-Fosfato Segundo Norma NBR 7397}

Para a obtenção dos resultados de teor de fósforo presente no filme de pré-fosfato na condição inicial das amostras e após os ensaios de desengraxe, foi utilizada a norma NBR 7397 [4]. Este procedimento consiste em realizar a decapagem das amostras com uma solução de acido clorídrico com adição do inibidor de corrosão. Após remoção do revestimento de zinco e dos filmes de pré-fosfato e óleo, o teor de

* Contribuição técnica ao $51^{\circ}$ Seminário de Laminação - Processos e Produtos Laminados e Revestidos, 28 a 31 de outubro de 2014, Foz do Iguaçu, PR, Brasil. 


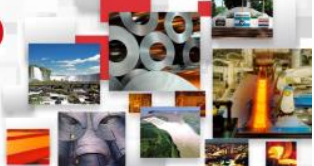

fósforo é determinado por meio da técnica de Espectrometria de Emissão Atômica com Plasma Acoplado Indutivamente - ICP.

\subsection{Microscopia Eletrônica de Varredura - MEV}

Realizou-se análise topográfica por meio de Microscopia Eletrônica de Varredura MEV das amostras antes e após os ensaios de desengraxe, com objetivo de avaliar o aspecto superficial quanto à distribuição do filme de pré-fosfato. Assim, foi empregado o modo de observação Elétrons Retro-espalhados (BSE - Back Scattered Electrons), onde por meio deste, foram realizadas microanálises por Espectrometria de Energia Dispersiva (EDS - Energy Dispersive Spectrometry).

\section{RESULTADOS E DISCUSSÃO}

\subsection{Ensaio de Embutimento}

A tabela 2 apresenta os resultados relativos ao ensaio de embutimento Erichssen, onde determinou-se a profundidade do embutimento até a ruptura do material, conforme a norma NBR 5902 [3].

Tabela 2: Resultados de profundidade de embutimento Erichsen.

\begin{tabular}{|c|c|c|c|c|c|}
\hline \multirow[t]{2}{*}{ Corpo de Prova } & \multicolumn{3}{|c|}{$\begin{array}{l}\text { Embutimento } \\
\text { Erichsen }(\mathrm{mm})\end{array}$} & \multirow[t]{2}{*}{ Média (mm) } & \multirow[t]{2}{*}{$\begin{array}{l}\text { Média Geral } \\
(\mathrm{mm})\end{array}$} \\
\hline & $1^{\circ}$ & $2^{\circ}$ & $3^{\circ}$ & & \\
\hline Aço zincado com pré-fosfato 1 & 11,6 & 11,9 & 11,8 & 11,8 & \multirow{5}{*}{11,8} \\
\hline Aço zincado com pré-fosfato 2 & 11,8 & 12,2 & 12,0 & 12,0 & \\
\hline Aço zincado com pré-fosfato 3 & 11,9 & 11,7 & 11,8 & 11,8 & \\
\hline Aço zincado com pré-fosfato 4 & 11,9 & 11,8 & 11,8 & 11,8 & \\
\hline Aço zincado com pré-fosfato 5 & 11,7 & 11,9 & 11,7 & 11,8 & \\
\hline Aço zincado sem pré-fosfato 1 & 10,9 & 10,7 & 10,9 & 10,8 & \multirow{5}{*}{10,7} \\
\hline Aço zincado sem pré-fosfato 2 & 10,6 & 10,7 & 10,7 & 10,7 & \\
\hline Aço zincado sem pré-fosfato 3 & 10,8 & 10,6 & 10,8 & 10,7 & \\
\hline Aço zincado sem pré-fosfato 4 & 10,5 & 10,6 & 10,6 & 10,6 & \\
\hline Aço zincado sem pré-fosfato 5 & 10,5 & 10,6 & 10,6 & 10,6 & \\
\hline
\end{tabular}

De acordo com os resultados apresentados na tabela 2, verifica-se que o material aço zincado com filme de pré-fosfato apresentou profundidade de embutimento cerca de $10 \%$ maior que o material aço zincado sem filme de pré-fosfato.

\subsection{Determinação do Coeficiente de atrito}

A tabela 3 apresenta os resultados obtidos referentes ao coeficiente de atrito obtido em cinco pontos de cada material.

* Contribuição técnica ao $51^{\circ}$ Seminário de Laminação - Processos e Produtos Laminados e Revestidos, 28 a 31 de outubro de 2014, Foz do Iguaçu, PR, Brasil. 
Tabela 3: Resultados da medida do coeficiente de atrito.

\begin{tabular}{|c|c|c|c|c|c|c|}
\hline Material & Análise 1 & Análise 2 & Análise 3 & Análise 4 & Análise 5 & Média \\
\hline $\begin{array}{c}\text { Aço zincado } \\
\text { sem pré- } \\
\text { fosfato }\end{array}$ & 0,179 & 0,189 & 0,187 & 0,181 & 0,188 & 0,185 \\
\hline $\begin{array}{c}\text { Aço zincado } \\
\text { com pré- } \\
\text { fosfato }\end{array}$ & 0,142 & 0,147 & 0,147 & 0,144 & 0,143 & 0,145 \\
\hline
\end{tabular}

De acordo com os resultados apresentados na tabela 3, verifica-se que o material zincado com filme de pré-fosfato apresentou coeficiente de atrito aproximadamente $20 \%$ menor que o material zincado sem filme de pré-fosfato.

\subsection{Determinação da Eficiência de Desengraxe}

A Tabela 4 apresenta os resultados da medição da massa de pré-fosfato antes e após o ensaio de simulação do desengraxe de linha de pintura automotiva, para as 14 amostras representativas da camada de pré-fosfato aplicado em aço zincado, utilizado no presente estudo.

Tabela 4: Massa de pré-fosfato antes e após o desengraxe do filme de pré-fosfato obtido por meio da técnica ICP.

\begin{tabular}{|c|c|c|c|}
\hline \multirow{2}{*}{ Amostras } & \multicolumn{3}{|c|}{ Teor de $\mathrm{P}\left(\mathrm{mg} / \mathrm{m}^{2}\right)$} \\
\cline { 2 - 4 } & Antes do desengraxe & Após o desengraxe & Eficiência (\%) \\
\hline 1 & 616,0 & 30,6 & $95 \%$ \\
\hline 2 & 588,4 & 4,6 & $99 \%$ \\
\hline 3 & 615,7 & 4,6 & $99 \%$ \\
\hline 4 & 618,4 & 19,3 & $97 \%$ \\
\hline 5 & 617,2 & 6,4 & $99 \%$ \\
\hline 6 & 647,2 & 9,5 & $99 \%$ \\
\hline 7 & 654,6 & 12,3 & $98 \%$ \\
\hline 8 & 619,3 & 2,1 & $100 \%$ \\
\hline 9 & 532,9 & 10,4 & $98 \%$ \\
\hline 10 & 652,1 & 16,5 & $97 \%$ \\
\hline 11 & 616,0 & 4,0 & $99 \%$ \\
\hline 12 & 588,4 & 7,7 & $99 \%$ \\
\hline 13 & 615,7 & 1,8 & $100 \%$ \\
\hline 14 & 618,4 & 10,4 & $98 \%$ \\
\hline Média & 614,4 & 10,1 & $98,4 \%$ \\
\hline
\end{tabular}

De acordo com os resultados apresentados na tabela 4, verifica-se que os teores de fósforo após os ensaios de desengraxe são residuais, o que gera elevados níveis de eficiência de desengraxe, com média acima de $98 \%$. Verifica-se também que não houve saturação do banho, visto que a eficiência de desengraxe apresenta-se semelhante ao longo do ensaio. A Figura 3 apresenta as eficiências de desengraxe da metodologia de simulação laboratorial ao longo dos ensaios para ambos os materiais testados.

* Contribuição técnica ao $51^{\circ}$ Seminário de Laminação - Processos e Produtos Laminados e Revestidos, 28 a 31 de outubro de 2014, Foz do Iguaçu, PR, Brasil. 

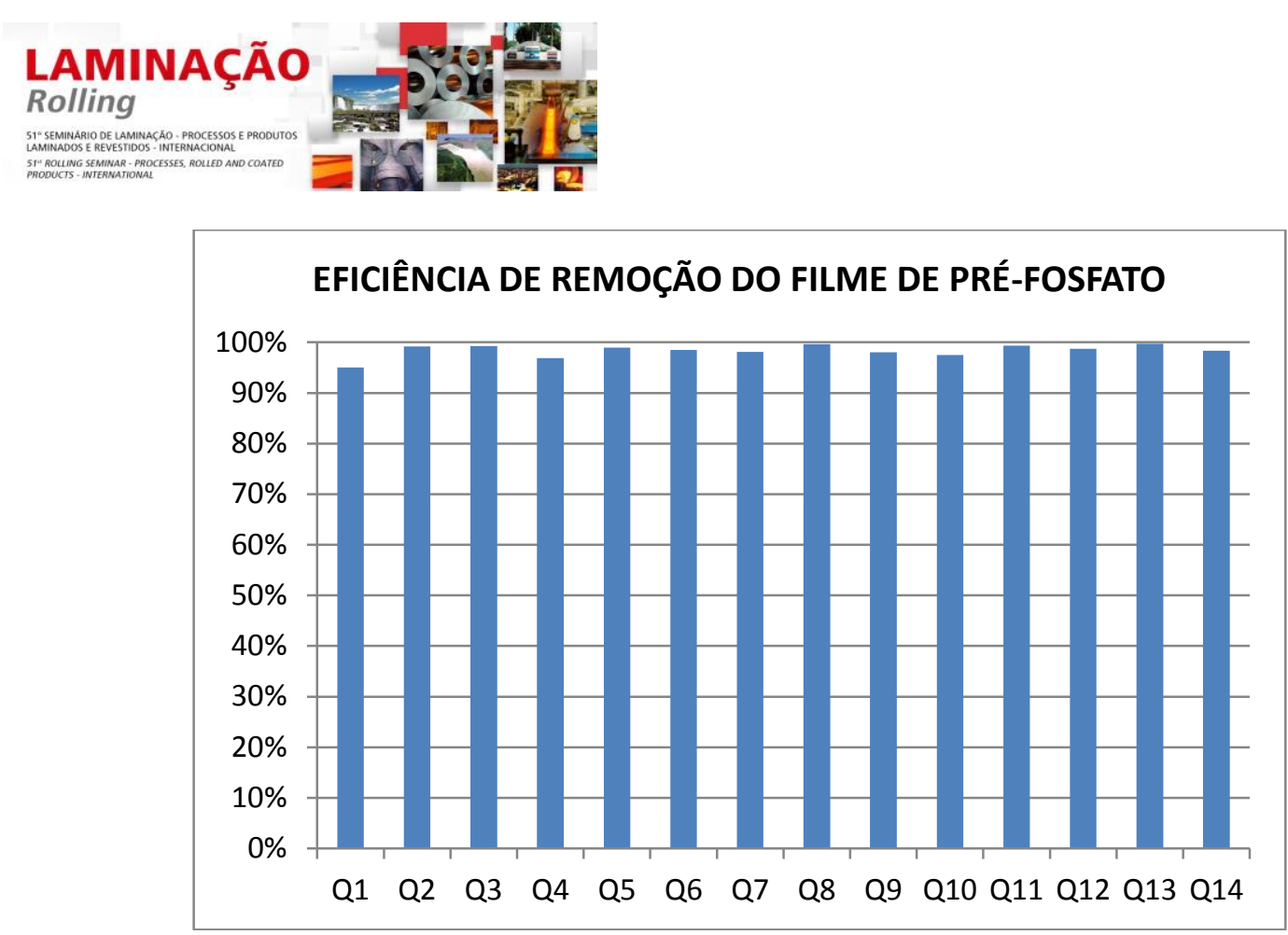

Figura 3: Eficiência de desengraxe para simulação do processo de desengraxe da linha de pintura automotiva para o pré-fosfato

A figura 4 apresenta as imagens e espectros obtidos pelas análises topográficas por Microscopia Eletrônica de Varredura - MEV para as 14 amostras utilizadas para determinação do teor inicial de fósforo antes do desengraxe.

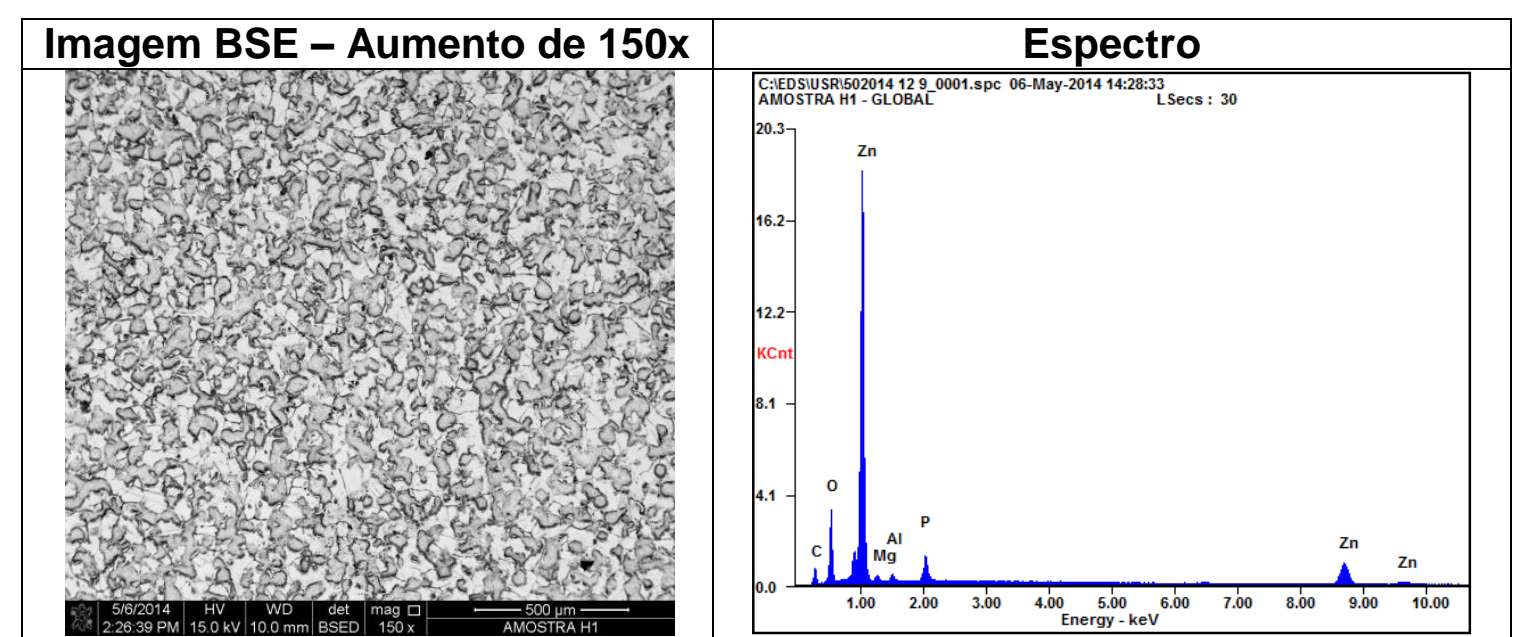

Figura 4: Resultados obtidos por Microscopia Eletrônica de Varredura das amostras pré-fosfato antes do ensaio de desengraxe de simulação laboratorial do processo de desengraxe automotivo

A figura 5 apresenta os resultados obtidos por Microscopia Eletrônica de Varredura após o ensaio de simulação laboratorial do processo de desengraxe industrial automotivo dos materiais com o filme de pré-fosfato. Realizaram-se imagens com 150 e 1000 vezes de ampliação, e obtidos seus respectivos espectros de fósforo. 

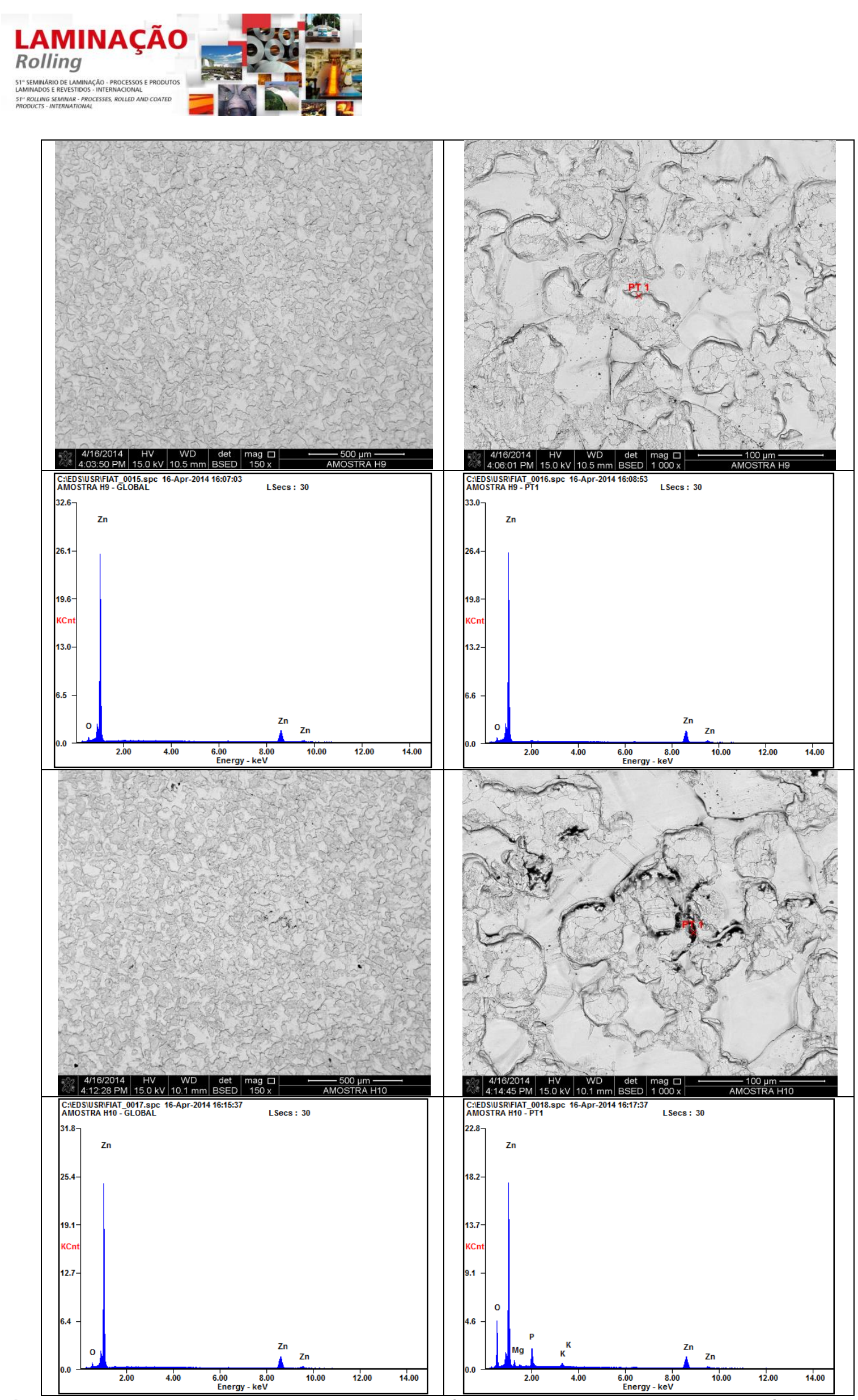

Figura 5: Resultados obtidos por Microscopia Eletrônica de Varredura das amostras Pré-fosfato após os ensaios de desengraxe de simulação laboratorial do processo de desengraxe automotivo

* Contribuição técnica ao $51^{\circ}$ Seminário de Laminação - Processos e Produtos Laminados e Revestidos, 28 a 31 de outubro de 2014, Foz do Iguaçu, PR, Brasil. 


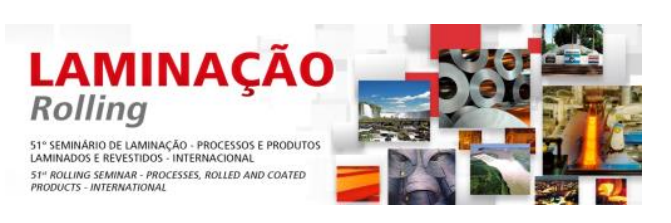

De acordo com os resultados apresentados na figura 4, verifica-se que a análise do aço zincado pré-fosfatizado antes da realização do ensaio de desengraxe, com a ampliação de 150 vezes, observa-se a presença de picos do elemento fósforo, característico da presença do filme de pré-fosfato na superfície do material (regiões escuras). Para a análise dos materiais após o ensaio de desengraxe, observa-se na figura 5 que as imagens de pequena ampliação (150 vezes), que apresenta uma imagem global do corpo de prova avaliado, quando foi observada a presença de regiões escuras, devido ao fato dessas regiões serem residuais, não houve formação de picos do elemento fósforo nos espectros. Nas imagens com 1000 vezes de ampliação, quando analisada uma região com resíduos de fósforo (regiões escuras), foi possível identificar picos do elemento fósforo, porém de baixa intensidade. Com isso, verificou-se que após o ensaio de desengraxe em laboratório, o aço zincado pré-fosfatizado apresentou elevada eficiência de desengraxe, com ocorrências de resíduos de fosfato em algumas amostras, semelhantes aos resultados obtidos por análise de ICP apresentados na tabela 4 .

\section{CONCLUSÕES}

Com base nos resultados, pode-se concluir que:

- O filme de pré-fosfato reduz o coeficiente de atrito do material, fazendo com que o mesmo apresente maior grau de estampabilidade.

- A eficiência média de desengraxe dos filmes de pré-fosfato apresentou-se acima de $95 \%$.

- O aço zincado pré-fosfatizado pode ser utilizado para a fabricação de peças críticas da carroceria de veículos sem prejudicar o processo de pintura automotivo.

\section{REFERÊNCIAS}

1 Freeman DB. Phospating and metal pré-treatment. 1st Ed. New York: Industrial Press. 1988: 83-102

2 Rausch W. The phosphating of metals. 1st Ed. Great Britain: Redwood Press. 1990:211-260.

3 Associação Brasileira de Normas Técnicas. NBR 5902: Determinação do Índice de Embutimento em chapas de aço pelo Método Erichsen , 1979.

4 Associação Brasileira de Normas Técnicas. NBR 7397: Produto de Aço ou Ferro Fundido Revestido de Zinco Por Imersão a Quente - Determinação da Massa de Revestimento por Unidade de Área - Método de Ensaio, 2007.

* Contribuição técnica ao $51^{\circ}$ Seminário de Laminação - Processos e Produtos Laminados e Revestidos, 28 a 31 de outubro de 2014, Foz do Iguaçu, PR, Brasil. 